\title{
Research on Experiment Teaching Mode of Chinese Tea Ceremony Based on Virtual Simulation Technology
}

\author{
Gao Yunxia ${ }^{1}$ \\ ${ }^{1}$ School of Literature and Media, Xi'an Fanyi University, Xi'an, Shaanxi, China
}

\begin{abstract}
Against the backdrop of developing new arts, it is urgent for undergraduate colleges engaged in applied studies to change the traditional teaching model and adopt virtual simulation technology to build an experiment teaching system for the studies of traditional Chinese culture, particularly the Chinese tea ceremony. In this paper, a multi-level experiment teaching system is developed based on experienceknowledge-skills with multiple objectives, covering two physical sections and four functional modules, featured by immersive and interactive teaching methods. It encourages learning based on independent inquiry, enabling students to be flexible for innovation. It effectively integrates good teaching resources to serve multiple disciplines, ultimately achieving the goal of enhancing competency, elevating spiritual pursuit, and raising awareness of innovation.
\end{abstract}

\section{Introduction}

Experiment teaching based on virtual simulation has become an important part of the information technology of higher education propelled by digital technology, which also challenges traditional liberal arts teaching models: on the one hand, the advocacy of new liberal arts requires the integration of new technology with traditional arts courses such as philosophy, literature, and language learning to develop a comprehensive interdisciplinary learning model. On the other hand, to cultivate students' competency in real practice and innovation, applied undergraduate colleges and universities urgently need to adopt experiment teaching mode and innovative learning model to enhance its teaching of applied arts. Particularly, it needs to employ virtual simulation technology and application of big data, interactive digital and intelligent technology to improve teaching effectiveness, expand the breadth and depth of teaching content, and extend the time and space of teaching.

Judged from the overall, although the application of virtual simulation technology in the arts field is relatively late, some national-level platforms have achieved remarkable results. For instance, some related research papers in the field of humanities are relatively mature, such as Exploration of Construction System of Chinese Poetry Education Experiment Teaching Platform based on Virtual Simulation: Exploring an Immersible, Nonlinear Teaching Mode [1]. It is based on Mr. Ye Jiaying's Academy with sufficient and rich modules and contents, which is instructional. However, it has not delved deep into the virtual simulation of the tea ceremony, an important part of traditional Chinese culture. To promote the teaching research, inheritance, and dissemination of excellent Chinese traditional culture, virtual simulation technology is applied to the teaching of Chinese Tea Ceremony with regional and professional characteristics, giving full play to the immersive and interactive features of experiment teaching. It aims to cultivate innovative talents for traditional culture to adapt to the new environment.

\section{The purpose and idea of experiment teaching of Chinese Tea Ceremony based on Virtual Simulation}

Chinese tea culture has enjoyed a long-standing history in China, which can be dated back to Wei and Jin Dynasty. It has become an important part of Chinese people's social and spiritual life. Tea ceremony has also been used to cultivate a clean government and demonstrate frugality. It has formed a system through thousands of years' evolvement. It has become a compulsory course for modern Chinese to elevate his humanity quality in the rejuvenation of Chinese culture. As it plays a proactive role in promoting students' ethics and education at university, tea ceremony has been extensively discussed. Therefore, both the distinctive inherent features of tea ceremony culture and methodologies of virtual simulation need to be taken into consideration during the virtual simulation of tea ceremony culture.

\subsection{The target to improve students' self- cultivation based on experiment sharing and openness}

Broadly speaking, Chinese ceremony culture has been well embedded in people's daily with its profound cultural

" Corresponding author: gaoyunxia@xafy.edu.cn, gaoyunnxia@163.com 
connotations and rich ceremonies. It can help people to achieve self-healing constantly against budging material greed, amid the specialization of schools and disciplines. Perception, emotions, attitudes, and behaviors are engaged, no matter it is an attempt of tea drinking, tasting, or participation in tea ceremonies. "It can be a feasible solution to overcome the crisis in the fragmentation of human attainment due to overspecialization." [2] Human attainment is not a simple accumulation of knowledge but conditioned upon the practitioner's deep immersion into its cultural system. A person can acquire all-directional perception through experience. Virtual simulation technology can replicate the real environment to endow the learner with substitution experience to break through boredom and monotonousness of time and space restraints.

\subsection{The target of emotional acquisition based on an immersive cultural experience}

The experiment teaching mode of tea ceremony should adopt the traditional tea ceremony techniques as its experiment perception and immersion objects. Chinese tea culture has become an embodiment of natural feelings and emotions since its development through Wei, Jin, Tang, Song, Yuan, Ming, and Qing Dynasties. Tea is taken as an object of emotional attachment (drinking environment, tea utensils, tea chambers, etc.). The process of tea drinking and digestion from bitterness to sweetness is analogous to human life course, as all kinds of emotions (thoughts, feelings, friendship, etc.) accompanying tea drinking will be transformed into rational judgments about wisdom and faith, endowing tea with sentiments and vice versa."[3] Therefore, reflections of life, life philosophy embodied in the tea ceremony culture will be linked with life stories familiar to the learner through context setting.

\subsection{The target of innovation of ideas based on an interactive concept}

Being interactive is one of the key features of virtual simulation technology, which enhances communication between the virtual environment and humans. That is, humans control the environment through natural behaviors (language and movements) while the virtual environment also reacts to such behavior. The tea ceremony culture system is presented through virtual simulation. Comprehensive innovation needs to be combined with regional characteristics in terms of technical methods and expressions. Firstly, as an object, tea has its material nature such as category and quality of tea, time, and season suitable for tea drinking, etc. Secondly, tea drinking is a process, involving the external environment (layout of the tea chamber and decorations), tea pals, etc. Lastly, Zhongnan Mountain forms the natural boundary between the north and south of China in terms of geography, ecology, climate, environment, and even humanity. It is a solid base and a magnificent barrier for Chang'an, the ancient capital of China. It is the birthplace of Buddhism, Taoism, and culture of life span and being filial. Through contextual setting, it presents perfect integration and interaction between the mountain and tea, between humans and machines, and between the ancient and modern.

\section{System architecture and R\&D technology of the experiment teaching of Chinese Tea Ceremony based on Virtual Simulation}

Based on Chinese tea ceremony culture " Where is the way? Tea has been the essence from ancient till today", the Virtual Simulation Experiment Teaching Management Platform relies on computer simulation technology, multimedia technology, and network technology to achieve seamless connection of data interfaces, record and track the whole experiment process. It is developed with a service-oriented software architecture to integrate physical simulation, innovative design, intelligent guidance, automatic correction of virtual experiment results, and teaching management.

\subsection{Function modules and system architecture}

The multi-level Experiment teaching system is developed based on experience-knowledge-skills with multiple objectives, covering two physical sections and four functional modules. The platform is divided into four modules:

- Tea art: tea history, category, brewing methods, tea ceremony and tea $\operatorname{art}($ knowledge)

- Tea awakening at Zhongnan: 4 settings in four different seasons (experience)

- Zhongnan tea chamber: design of tea chamber (design)

- Tea show at Zhongnan: brewing of tea (appreciation)

The platform construction system adopts a four-layer architecture, including the application layer, simulation layer, service layer, and support layer. As shown in the table, each layer offers services to its upper layer until the construction of the specific virtual experiment teaching environment is completed.

\subsection{R\&D technology}

It adopts $\mathrm{C} / \mathrm{S}$ architecture. The server-side management system adopts the J2EE framework (Structs + Spring + Hibernate), and the client-side virtual experiment platform adopts Unity3D technology. It can support more than 10,000 people online simultaneously. 
Table 1 The main research and development technology of virtual teaching experiment of Chinese tea culture ceremony

\begin{tabular}{|c|c|}
\hline Index & Content \\
\hline $\begin{array}{l}\text { Development technology (such as 3D simulation, } \\
\text { VR technology, AR technology, animation } \\
\text { technology, WebGL technology, OpenGL } \\
\text { technology, etc.) }\end{array}$ & 3D simulation technology, animation technology \\
\hline $\begin{array}{c}\text { Development tool (such as VIVE WAVE, } \\
\text { Daydream, Unity3d, Virtools, Cult3D, Visual } \\
\text { Studio, Adobe Flash, Baidu VR content display } \\
\text { SDK, etc.) }\end{array}$ & $\begin{array}{c}\text { Basic modeling: 3DMAX, MAYA } \\
\text { Browse the scene: Unity3D } \\
\text { Control: Visual Studio } \\
\text { Other knowledge points: Adobe Flash, PhotoShop }\end{array}$ \\
\hline $\begin{array}{l}\text { Project quality (such as total faces of a single scene } \\
\text { model, texture resolution, rendering times per frame, } \\
\text { action feedback time, display refresh rate, resolution, } \\
\text { etc.) }\end{array}$ & $\begin{array}{l}\text { The total faces of a single scene model: } 500000 \text { faces; } \\
\text { texture resolution: } 1024 * 1024 \\
\text { Display frame rate: higher than } 30 \text { frames per second; } \\
\text { refresh rate: higher than } 30 \mathrm{~Hz} \\
\text { Normal resolution } 1920 * 108\end{array}$ \\
\hline Development language (e.g., JAVA.Net, PHP et al.) & C\#. JAVA, PHP \\
\hline $\begin{array}{l}\text { Development tool (Such as Eclipse, Visual Studio, } \\
\text { NetBeans, Baidu VR classroom SDK, et al.) }\end{array}$ & Eclipse \\
\hline $\begin{array}{c}\text { Database adopted (such as HBASE, Mysql, SQL } \\
\text { Server, Oracle, et al.) }\end{array}$ & MySQL \\
\hline
\end{tabular}

\subsection{Experiment method}

\subsubsection{The situational immersive experiment teaching method provides students with virtual scenes related to the tea ceremony}

The virtual story happens at Zhongnan Mountain. The relationship among tea, nature, and life is being explored in the story of the Tea Saint $\mathrm{Lu} \mathrm{Yu}$ and the poets of the Tang Dynasty, to help students taste the connotations of the tea ceremony. The virtuous settings are featured by changes of the four seasons in the Zhongnan Mountain and distinguished by varieties of tea utensils, tea, and tea water to stimulate sensually through sound, forms, color, and inspire awakening and insight into the traditional Chinese culture.

\subsubsection{Teaching method based on interactive and voluntary acquisition}

Students need to complete learning of tea art knowledge, setting up the tea room, and making tea independently. In the independent design, students will complete the related operation on tea and music, calligraphy and painting, poetry, and the selection of parameters in the tea art process to improve practice. During the whole teaching process, students will operate independently to realize a change in settings. The experiment will provide feedback on students' learning.

\section{The implementation process of experiment teaching of Chinese Tea Ceremony based on Virtual Simulation}

A student is required to $\log$ in to the experiment virtuous simulation platform with a personal account. He will complete and pass three links to realize the transformation of experience-knowledge-ability: The first link, emotional experience assignment will transport students into the situation of the hero through changes of settings and dialog to penetrate the relations between tea and human, linking tea and tea appreciation with Chinese sentiments. Second link, knowledge acquisition will be implemented through browsing the tea art knowledge database and test; third link, application of assignments requires students to design tea chambers, choosing appropriate natural landscapes, calligraphy, and paintings, classic music, utensils, etc. Brew the tea according to standard brewing procedures to acquire fragrance value and complete the tea appreciation process to be awarded a final grade and generate an e-certificate.

\subsection{Interaction operation instructions for students}

Section 1: Tea Awakening at Zhongnan

The student will replace $\mathrm{Lu} \mathrm{Yu}$, the hero of the story, to travel in the scene. First setting: Life story and tea culture ceremony in Spring; Second Setting: Life story and tea culture ceremony in Summer; Third setting: Life story and tea culture ceremony in the Fall; Fourth setting: Life story and tea culture ceremony in Winter, enhancing understanding the link between tea and life. Knowledge points will be tested in the four settings to facilitate students to learn knowledge related to tea history, categories, skill, and ceremonies. 
Section 2: Tea Chamber at Zhongnan

- Phase I: Design of tea chamber, including the naming of tea style, tea room layout, and arrangement of utensils on the tea table.

- $\quad$ Phase II: Tea ceremony learning, including tea appreciation, boiling water and cleaning utensils, warming pot, placing tea, making tea, draining tea, dividing tea, and drinking;

- Phase III: Exhibition of tea at Zhongnan, including a selection of tea and tea sets, determination of brewing water temperature and brewing time

Completion of tea making, with a close-up of the tea being poured into the cup, showing the brewing is complete.

Students will be assessed based on their optimal configuration, total time consumed, design descriptions, and taste judgment, with an e-certificate generated.

\subsection{Assessment requirements and evaluation system}

Students are required to complete their trip of the tea ceremony and feel what is embodied and finish the ten exercises for $\mathrm{Lu} \mathrm{Yu}$;

Students are asked to master tea ceremony culture and relevant knowledge points and finish the test on tea art records;

Students are required to design the tea chamber and make the tea, who need to choose at least one type of tea to brew. He will demonstrate the complete tea art process. Students are required to brief his design ideas and feelings of tea tasting and complete the final report;

Students are required to stage a show off-line to train their teamwork and collaboration.

Performance assessment system: Based on the contextual setting, a person's selection of tea variety, tea weight, water source, water temperature, each brewing step and brewing time will determine whether the tea art process is successful or not and whether the brewed tea meets the color, fragrance and taste standards. Besides, tea types, development history, brewing techniques for the six types of tea (green tea, yellow tea, white tea, green tea, black tea, dark tea), tea etiquette, and tea utensil recognition and appreciation will also be tested. All those contents will be tested through a variety of means such as test paper, technical operation, experiment reports, etc. The experiment teaching management platform based on virtual simulation will automatically record data related to student information, the most optimized match data, experiment report, time, etc. Performance Report will be a comprehensive assessment based on subjective evaluation.

\section{Advantages of experiment teaching mode of Chinese Tea Ceremony based on virtual simulation technology}

The experiment teaching of tea ceremony based on virtual simulation is an extension and expansion of traditional teaching, which achieves the target of telling a good story, cultivate sound competence, and practice deft skills. Through the virtual experience of the story, students are introduced into the historical situation to experience the development process of tea. It creatively uses the tea saint $\mathrm{Lu}$ Yu's virtuous life at Zhongnan Holy Land to link the connotation and art of tea, the process of symbolization, human cultivation, and internal experience. It follows the law on four seasons and five elements of tea ceremony to explore our understanding of various types of tea and respective brewing procedures, integrating nature, art, humans, and mentality into the process. In this way, the tea ceremony is shown as a form of culture, involving practice of various skills. As the online platform cannot completely replace the operation of the modern tea ceremony, the hybrid teaching mode to combine off-line operation can well make up this defect. Compared with traditional teaching, it has the following advantages:

\subsection{Comprehensive design of the experiment}

Many independent modules are set up to include a knowledge module, emotional module, and skills module, so that student can determine respective experiment scheme (such as the design of team chamber) and experiment parameter selection (such as choice of tea utensils, tea variety, and brewing method) to simulate the project virtually. Priority is given to design instead of operation, which is more helpful in cultivating students' capability in comprehensive design and creative thinking.

\subsection{Functional diversity of learning mode}

This virtual simulation teaching experiment system breaks the limitations of time and space. Based on virtual simulation teaching resources, students can independently learn online and perform simulation operations repeatedly according to their mastery; they can also be aware of their mastery of knowledge through self-assessment and test. Moreover, the virtual experiment system can memorize and display the students' operating process online, which is a good formative assessment method. It can be divided into three types of modes.

- Experience mode takes students into the story as a substitution of the hero to link between tea ceremony and life and nature and induce refection, improving students' empathy and virtuous cultivation.

- $\quad$ Practice mode enables students to go through the tea brewing procedures underwritten guidance and visual reminders. It will give a score for students' operation but will record user operation and online time for backstage administration. It is closely related to real applications, so it can ultimately enhance students' ability in innovation and design.

- Test mode requires students to complete knowledge learning of tea art and independent experiment, written creative interpretation of chamber design, and taste appreciation independently at one time without any instructions or reminder. After completion, a 
grade certificate will be awarded based on its performance. User operation and online time will also be recorded in the system.

\subsection{Opening and sharing combination between the real and the virtual}

The system combines both the online virtual simulation and offline practice, which can expand the display of results, and combine with the physical functions of the off-line Chinese culture workshop. The service target can be expanded not only to colleges but to all the teachers, students, overseas students, or visitors of the Chinese culture workshop. It provides students with the immersive learning experience, teaching, and dissemination of culture and knowledge. Combined with various social clubs such as Calligraphy and Painting Association, Tea Art Club, College Student Art Troupe, this simulation software can diversify the activities to present tea art show for visitors to the campus and demonstrate the charisma of traditional Chinese culture.

\section{Conclusion}

In response to the instructions of the Ministry of Education's on its latest development goals, the virtual simulation experiment teaching project should be committed to "improving students' ability in practice and innovation based on modern information technology and directed by the information content of experiment teaching urgently needed in related majors." It calls for "colleges and universities to actively explore a new model of personalized, intelligent, and ubiquitous experiment teaching combining online and offline teaching." Compared with traditional teaching mode, the experiment teaching mode of Chinese tea ceremony based on virtual simulation explores immersive and interactive teaching mode; it encourages self-learning based on exploration to boost independent innovation; it effectively takes advantages of excellent teaching resources to serve multiple disciplines, schools, and districts and is in line with the total target of talent cultivation of new arts subjects and applied undergraduate personnel.

\section{Acknowledgments}

This article is one of the phased achievements of the National Social Science Fund Project of Xi'anFanyi University- Research on the Teaching Practice of Chinese Ancient Literary Theory "Cultivation of Morality and Talents" (J20B40) under the Mixed Teaching Mode,alsoone of the phased achievements of theDoctoral Team Project ofXi'an Fanyi University-"Literary Geography and Regional Literature Research" (XFU17KYTDD03).

\section{References}

1. Li Xiaojuan, Tu Jun. (2017) Exploration of the Construction System of the Virtual Simulation
Experiment Teaching Platform for Chinese Poetry Education: Laboratory Research and Exploration, 12: 176-179.

2. Li Ping. (2019) On the Inner Relationship between Modern Humanistic Literacy and Chinese Tea ceremony. Guangdong Social Sciences, 6: 55-61

3. General Office of the Ministry of Education. (2017) Notice of the General Office of the Ministry of Education on the Construction of Demonstrative Virtual Simulation Experiment Teaching Projects from 2017 to 2020 (Jiaogao Ting Han [2017] No. 4) [EB/OL]. (2017-07-

11).http://www.moe.gov.cn/srcsite/A08/s7945/s794 6/201707/t20170721_309819.html

4. Zhu Yingyu. (2018) Virtual Simulation Teaching Resources and Talent Training Model Reform, Shanghai Jiaotong University Press, Shanghai. 